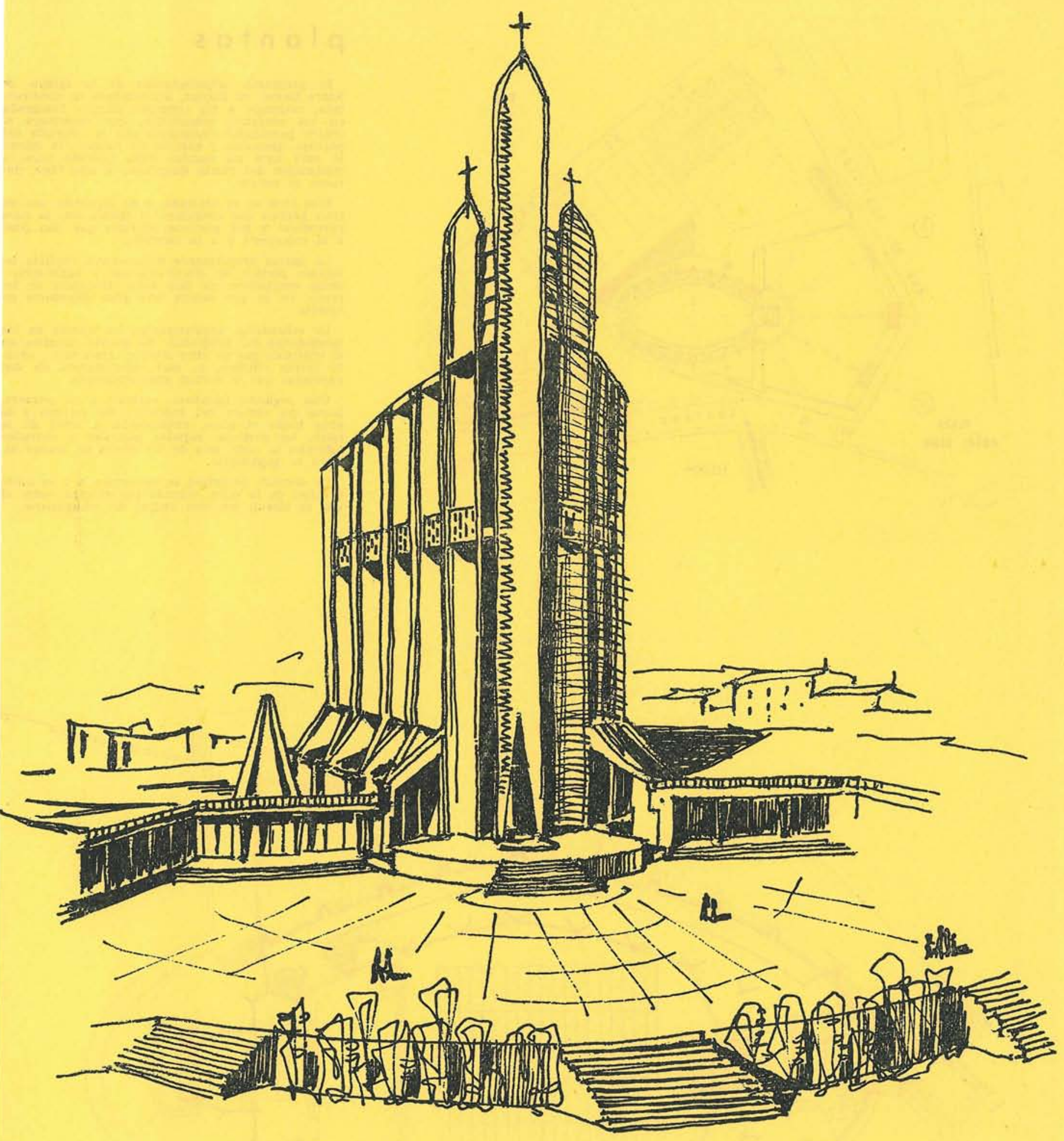

$148-47$

\title{
iglesia, en Royan
}

GUILLAUME GILLET, arquitecto. RENÉ SARGER, ingeniero 


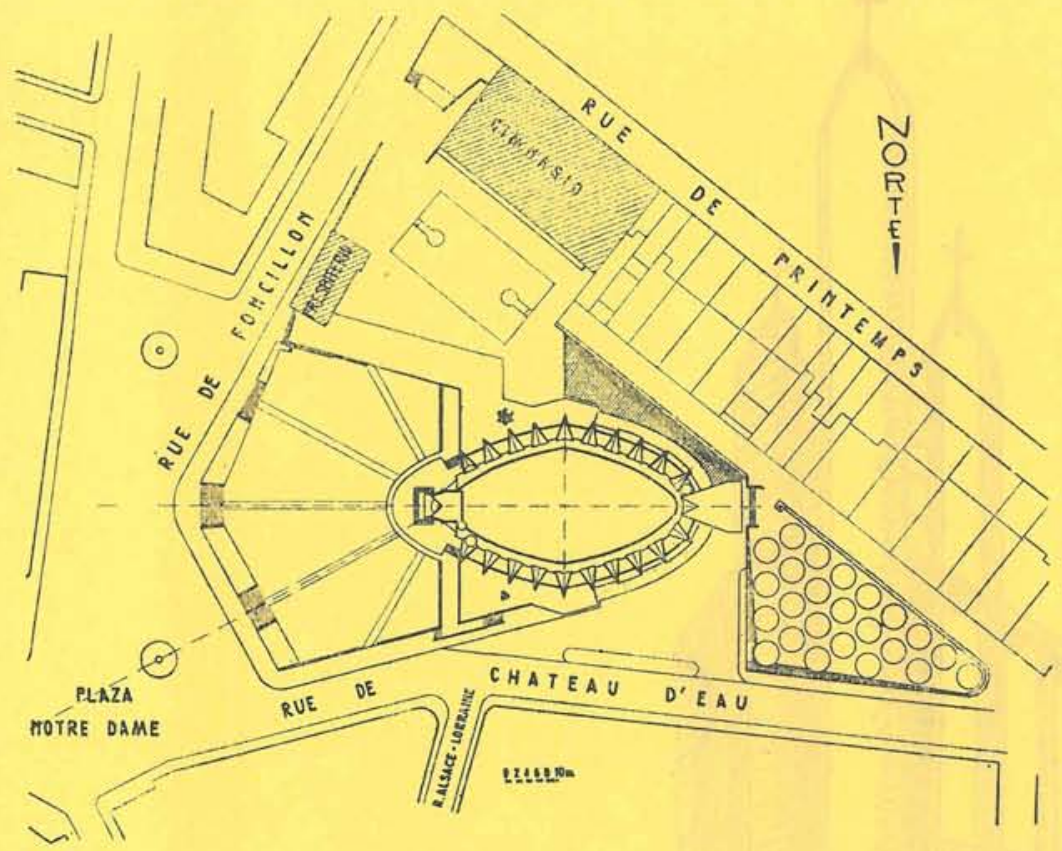

\section{plantas}

El programa arquitectónico de la iglesia de Notre Dame, en Royan, actualmente en construcción, responde a un concepto clásico. Integrada en un conjunto urbanistico, que constituye el centro parroquial-compuesto por la vivienda del párroco, gimnasio y campos de juego-, la iglesia. se abre ante un amplio atro, previsto para la rante el verano.

Este atrio se ve limitado, a su izquierda, por un gran portico que comunica la iglesia con la casa parroquial y por porticos laterales que dan paso a la catequesis y a la sacristia.

La iglesia propiamente dicha-nave, capillas laterales, portico de circunvalacion $y$ baptisteriorreno, en la que existía una gran diferencia de niveles.

$\mathrm{La}$ ordenación arquitectónica ha nacido de las necesidades del programa. Su planta, inscrita ei el triangulo que se abre sobre el gran atrio, adopta forma ellptica, o, mas exactamente, de dos parabolas que se cortan simetricamente.

Una segunda parábola, exterior a la primera, parte del vértice del tríángulo del terreno y se abre hacia el atrio, englobando, a nivel de la nave, los porticos, capillas laterales y entradas laterales al coro, una de las cuales da acceso di recto al baptisterio.

La entrada principal se encuentra a $4 \mathrm{~m}$ sobre el nivel de la nave, cerrada por el coro, sobre el que se elevan las tres agujas del campanario.

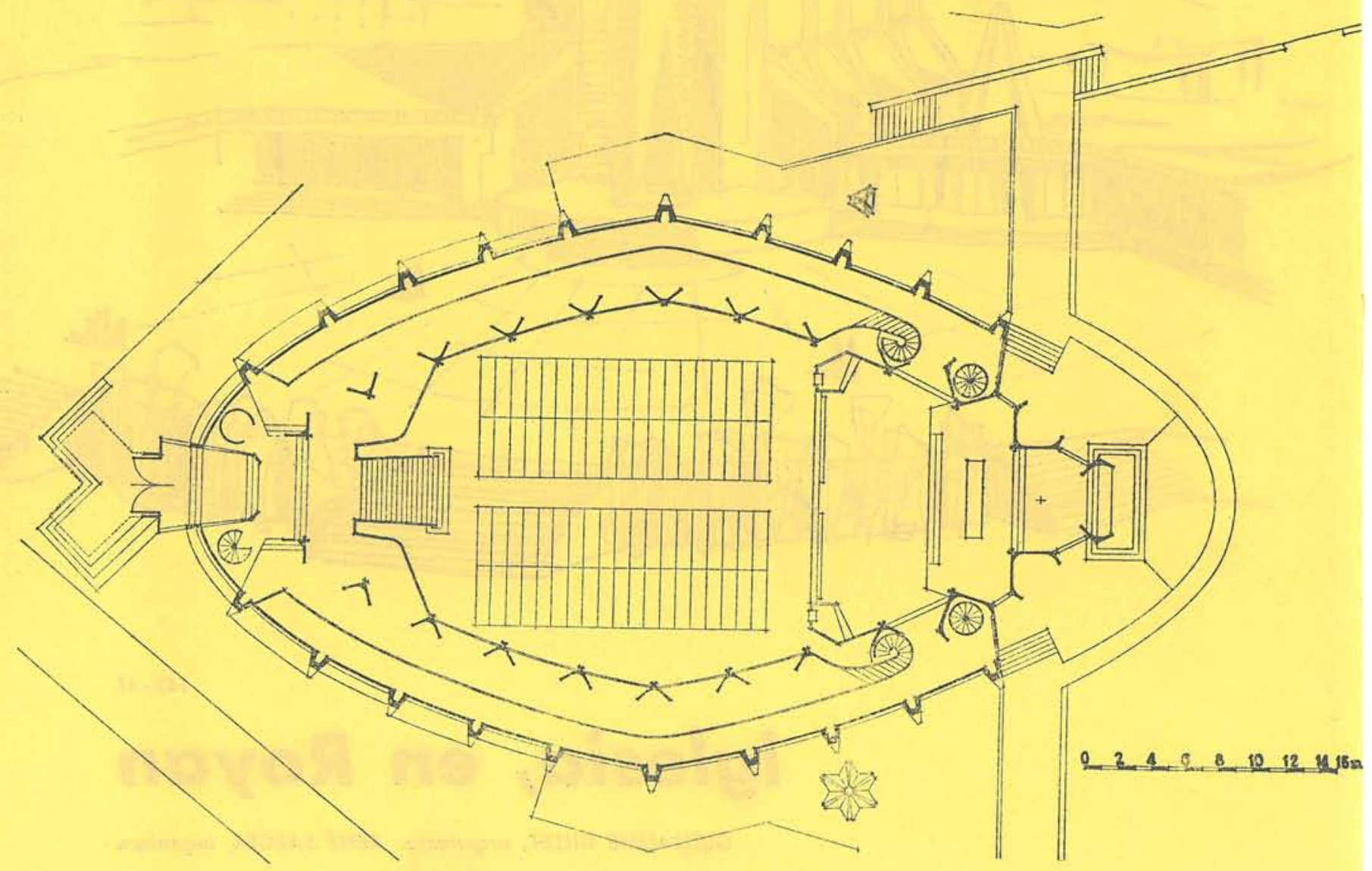




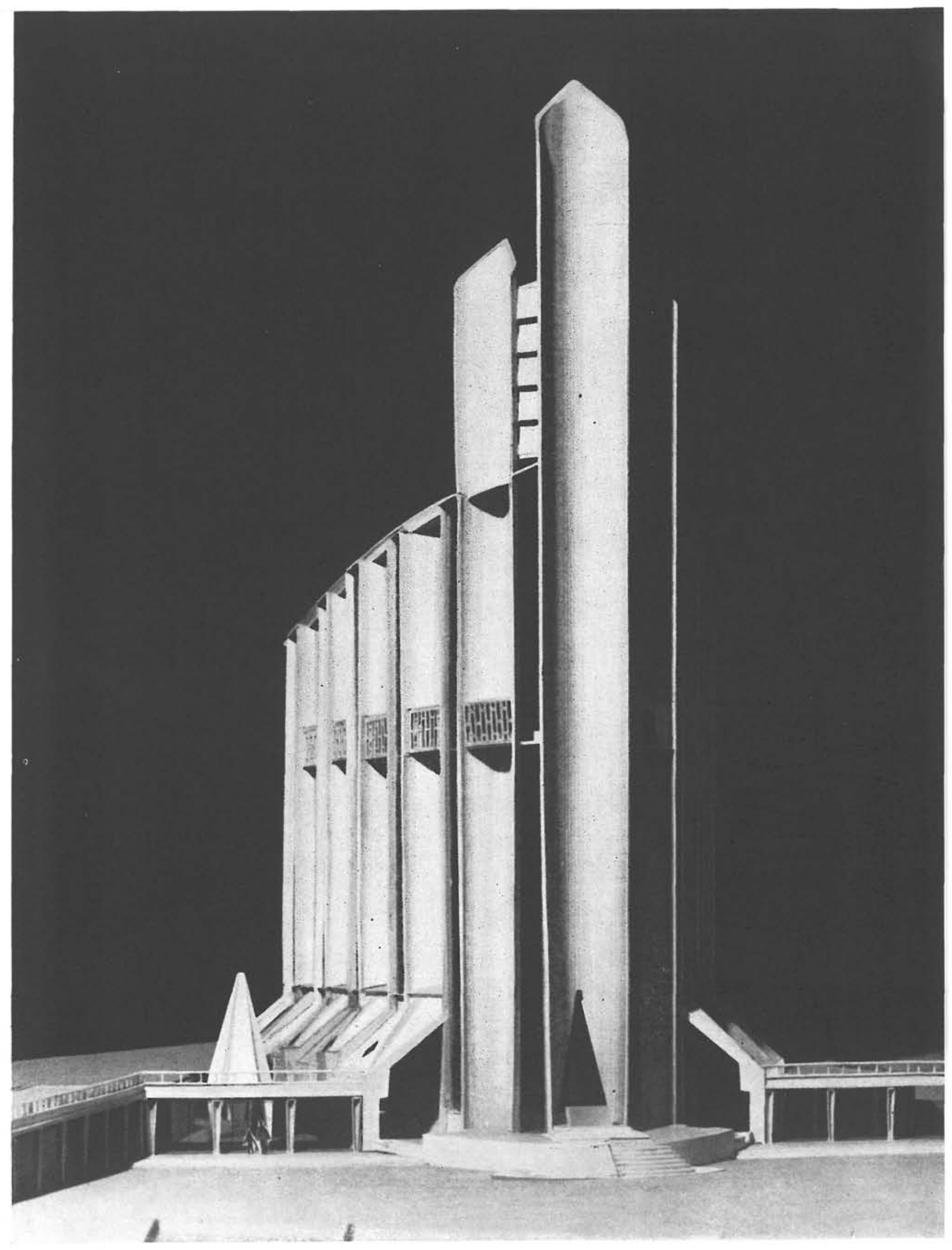

maque ta 


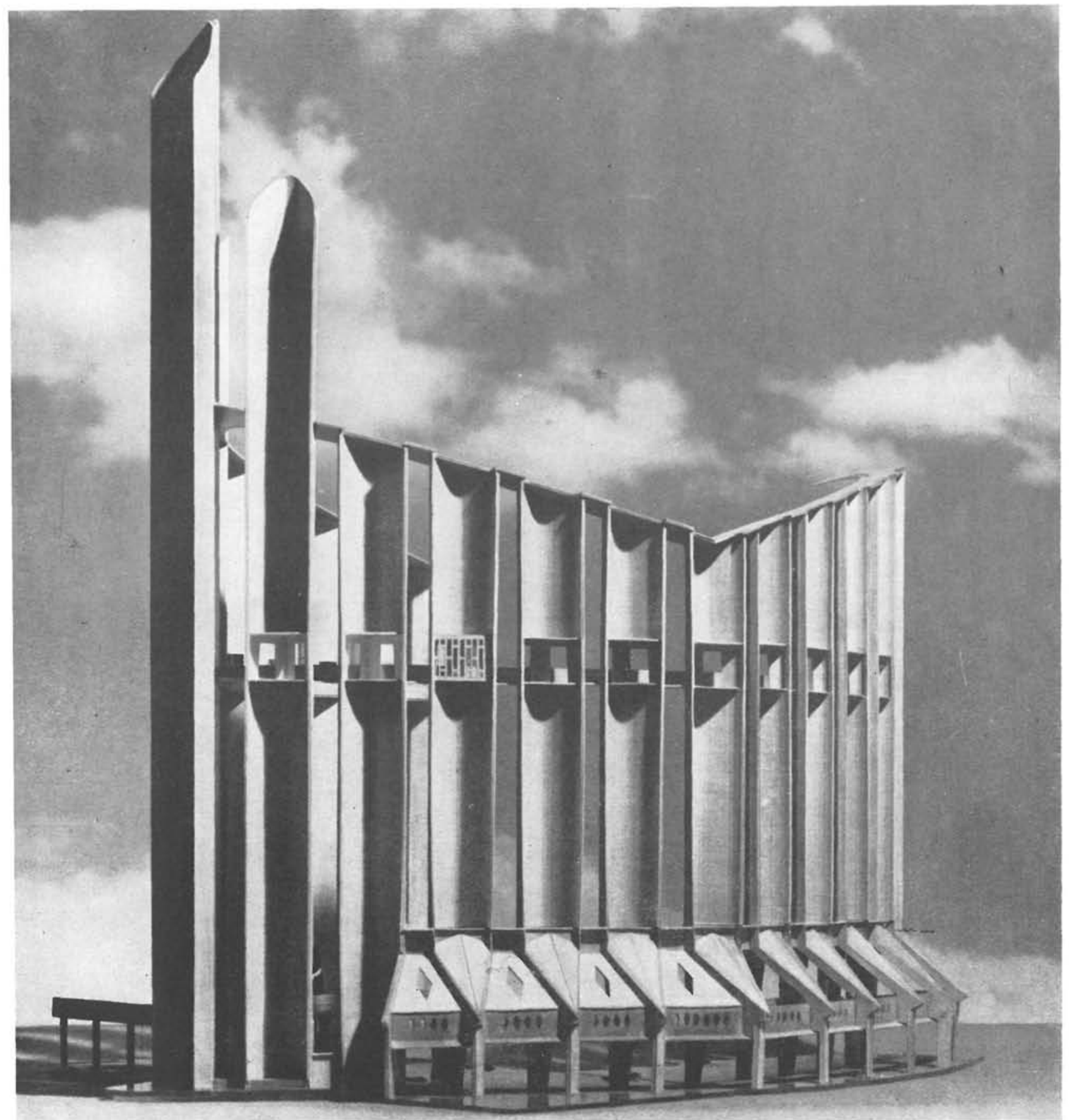

Los dos altares, el del interior de la nave y el del exterior del atrio, se encuentran frente s frente. El nivel del altar exterior está elevado, respecto a la nave y respecto al atrio, para que los fieles puedan oir misa, en verano, desde el interior o desde el exterior.

Junto a esta composición en planta, el arquitecto ha querido crear un volumen, delimitado por elementos constructivos de la más avanzada técnica, empleando láminas delgadas de hormigón armado, tanto en los elementos sustentantes verticales-de $10 \mathrm{~cm}$ de espesor $\mathrm{y}$ de más de $30 \mathrm{~m}$ d arcos de borde que forman la cornisa:

Los elementos sustentantes de la fachada están formados por membranas plegadas, de planta en V, abierta hacia el exterior. Estas "V", cuya parte interior está cortada en bisel, en vértice articulados, en semipórtico, que cubren los pasillos laterales de circunvalación. 

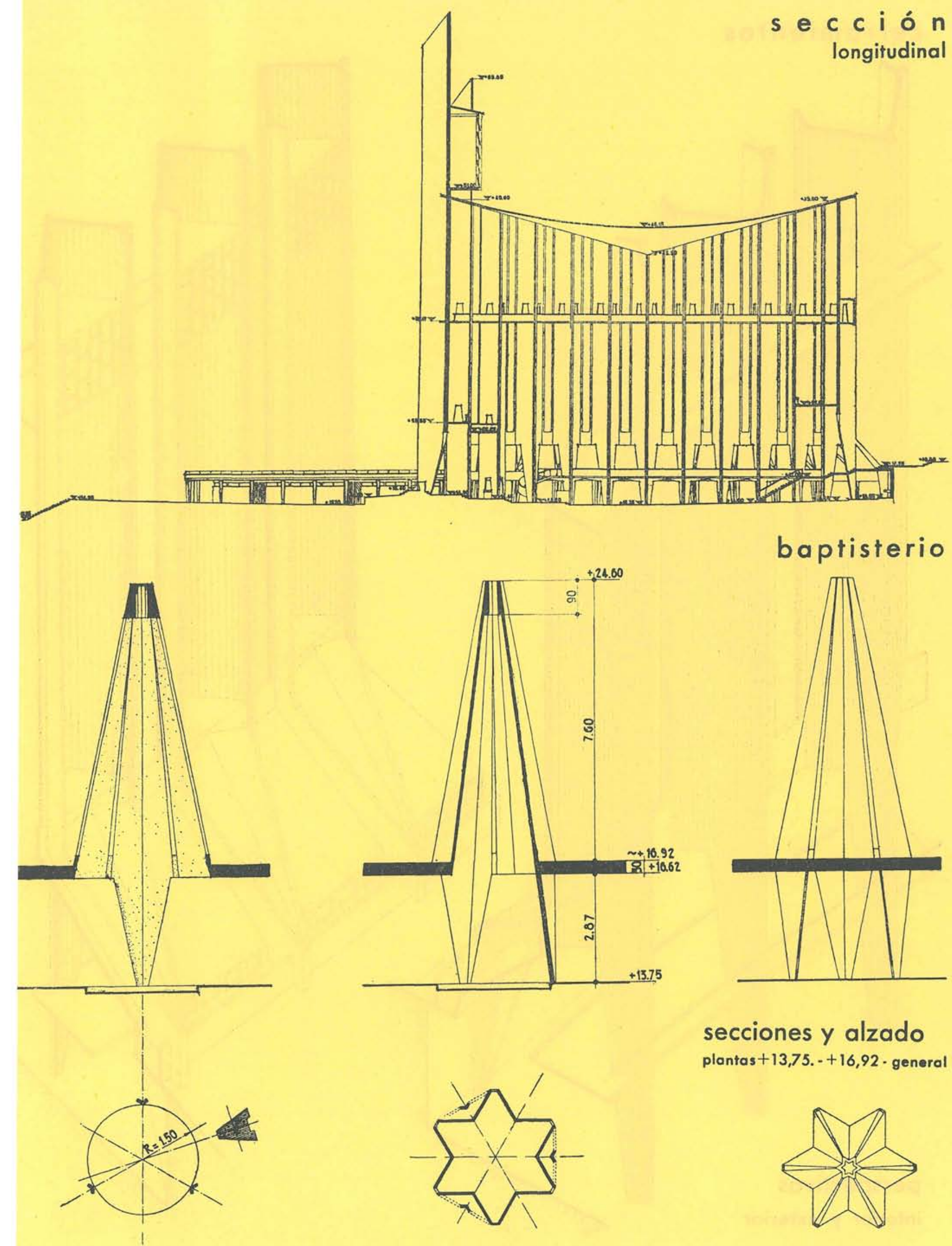

plantas $+13,75$. $-+16,92 \cdot$ general
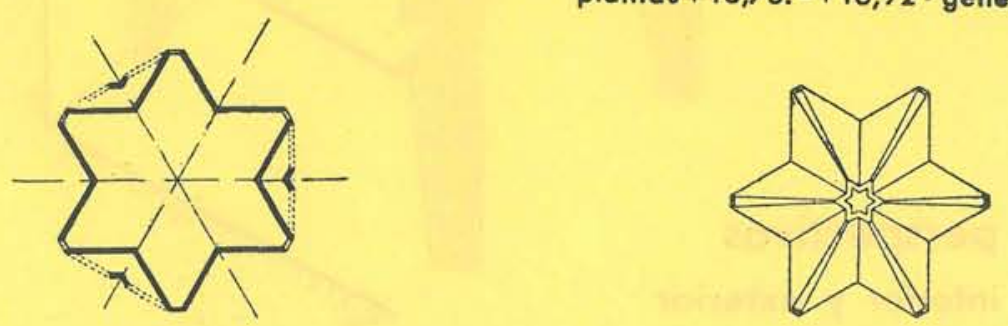


\section{cerramientos}

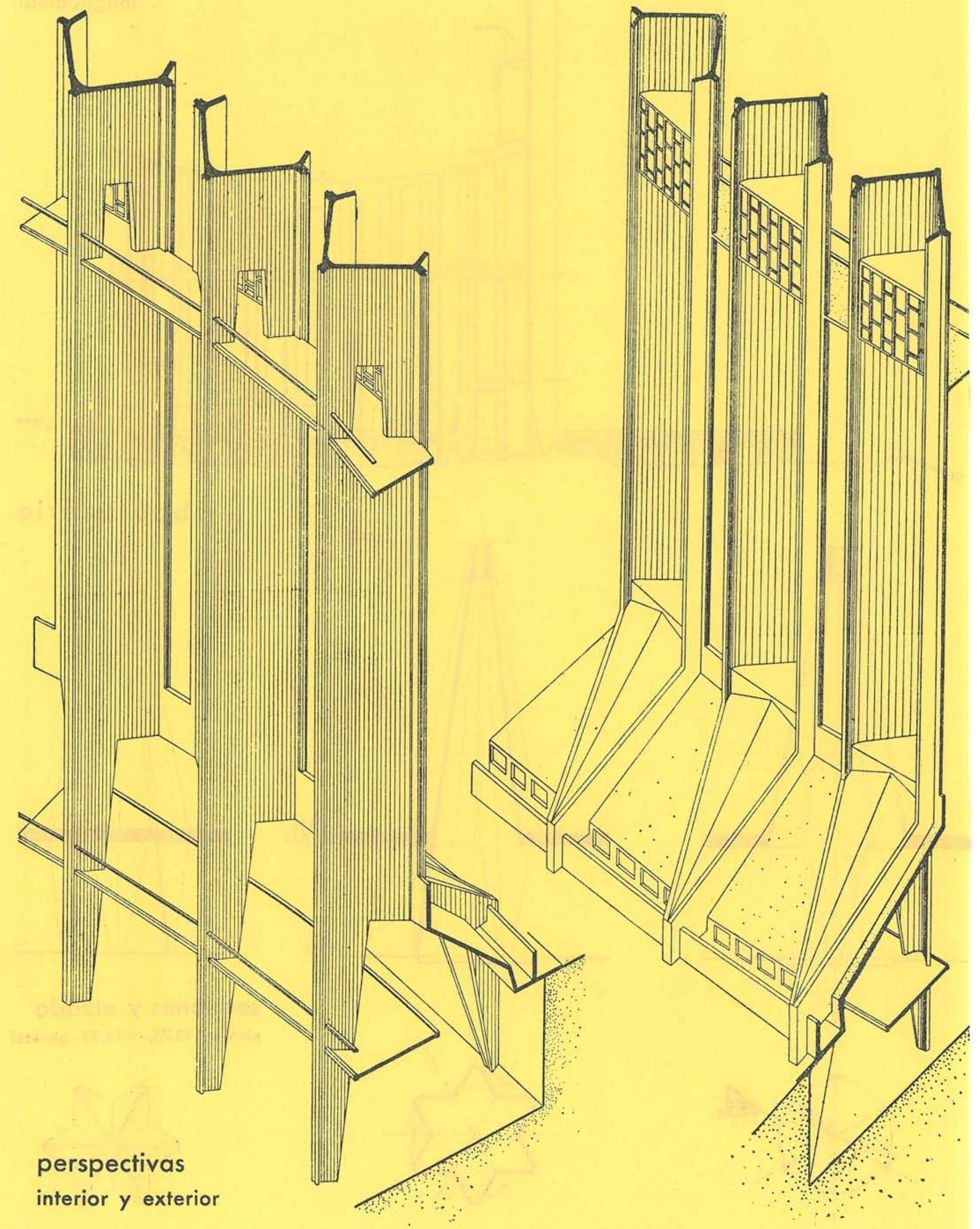




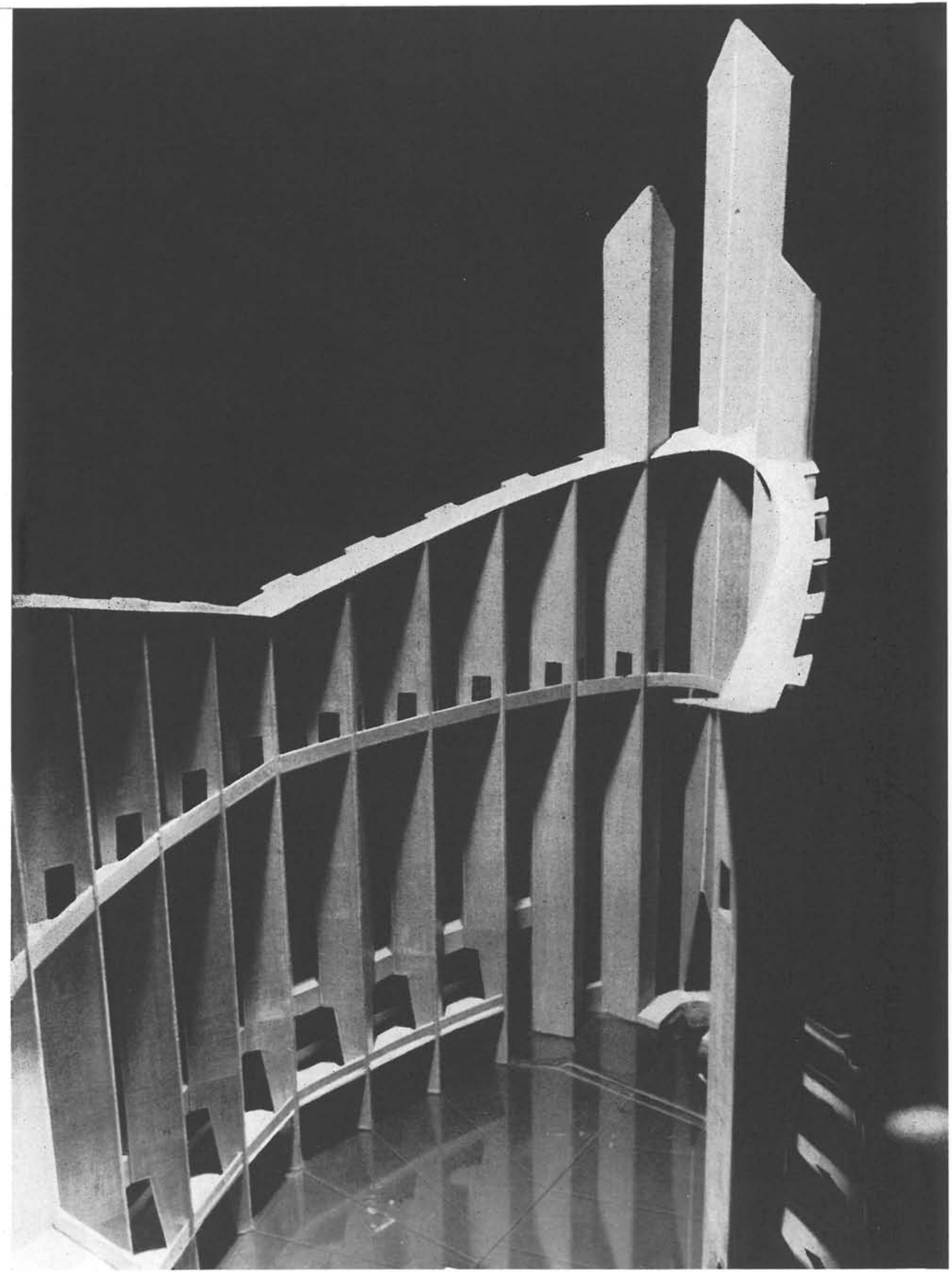

detalle interior 


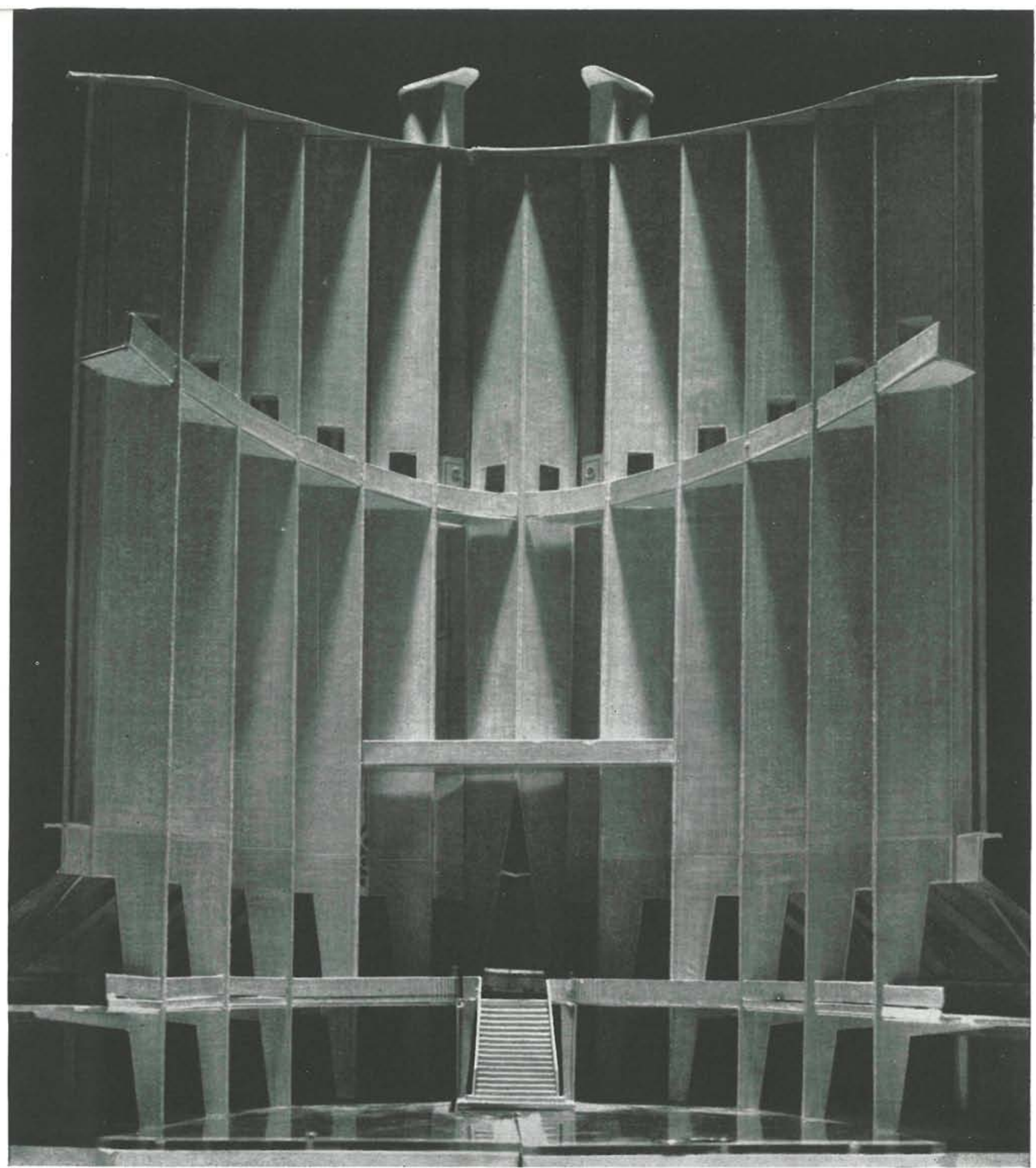

La originalidad de estos soportes, en lámina delgada de hormigón armado, se debe a la audaz concepción del ingeniero B. Lafaille, a cuya muerte, continuó su estudio y desarrollo su colaborador también ingeniero, R. Sarger.

La cubierta de la nave está formada por una lámina de doble curvatura, en forma de silla de montar parabólica. La cubierta de las zonas bajas está formada por una serie de láminas plegadas que atan unos con otros los pórticos-contrafuertes.

La técnica de la lámina plegada y cortada en bisel en su base, vuelve a repetirse en la construcción del baptisterio.
IN F O R M E S
D E
LA
C O NSTRU T T ION
92 

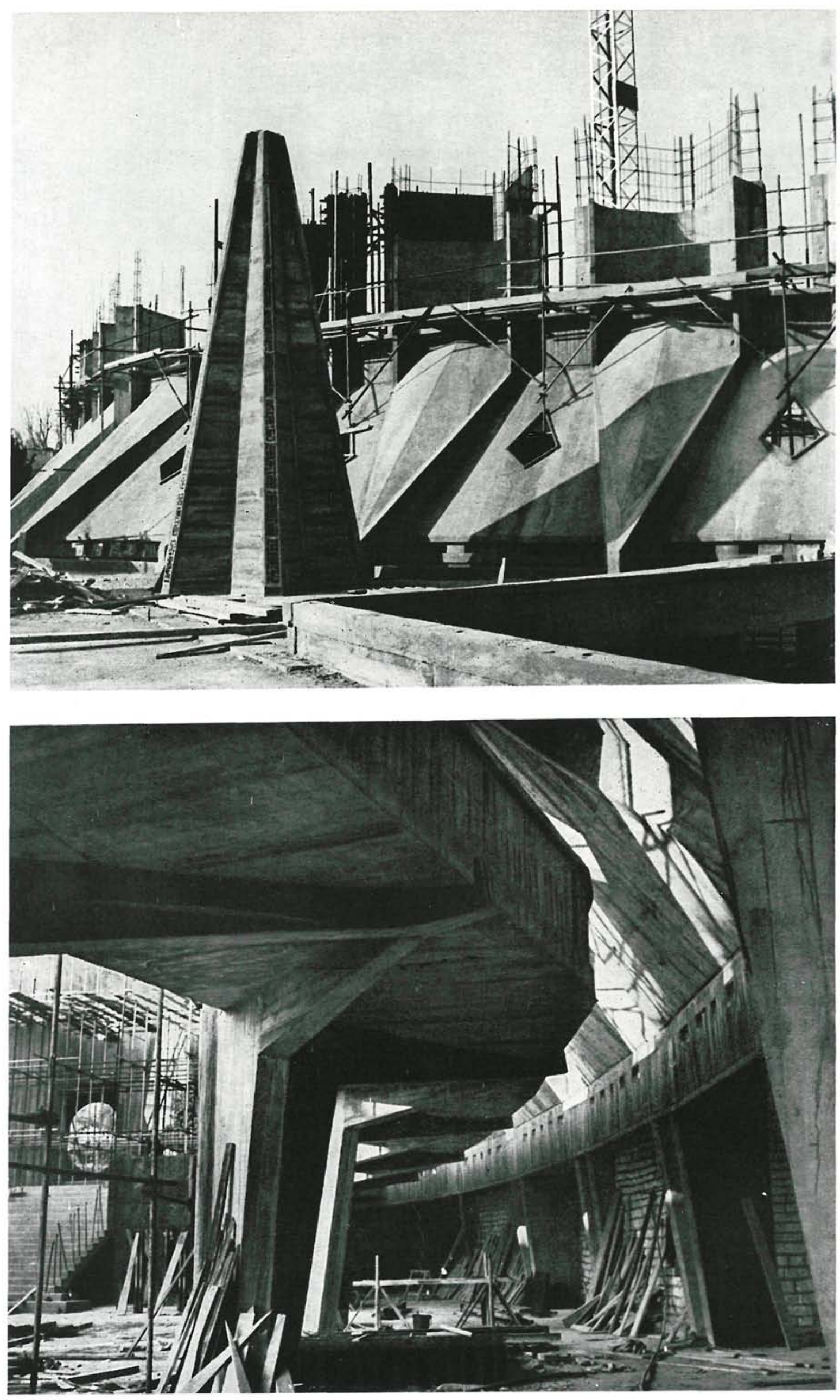

5
0
$u$
0
5
5
5
0
0 

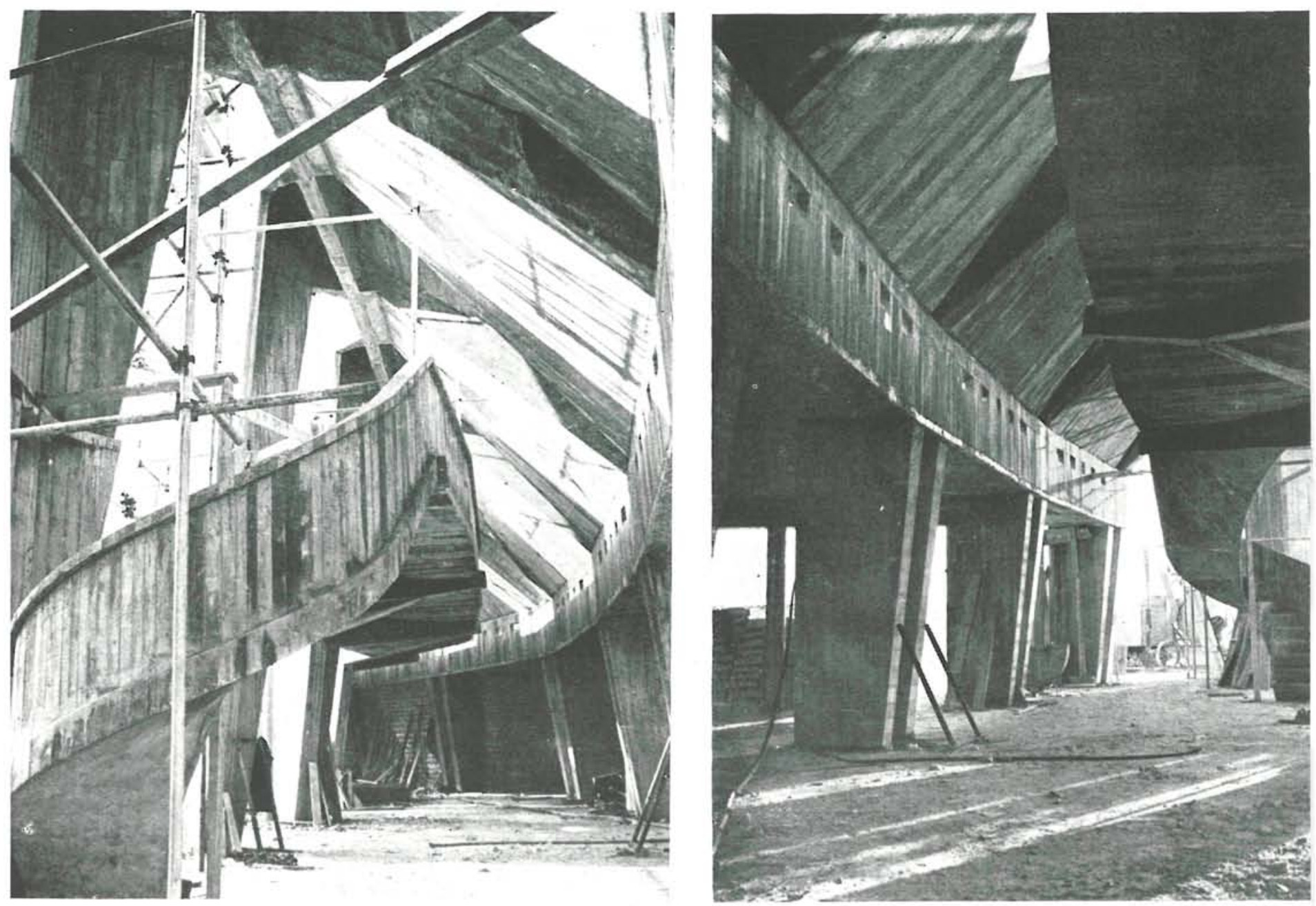

Fotost RED

Es de destacar la existencia de las dos coronas horizontales que zunchan el edificio a diferentes alturas, formando dos galerias, que transmiten los esfuerzos ocasionados por la acción del viento a las "V" principales de estabilidad, que flanquean, por una parte, el coro, y, por la otra, e porche de entrada. Estos últimos ele
los grandes pórticos estabilizadores.

La utilización clara y expresiva de elementos estructurales de nuestro tiempo, con un espíritu voluntariamente descarnado, ha permitido crear una unidad arquitectónica de grandeza monumental. Este puede ser el nacimiento de un estilo: los volumenes arquitectónicos, conforme van adquiriendo forma y medida, creciendo hacia el cielo, en esta iglesia de Notre Dame, de Royan, parecen
testimoniarlo.

A N F O R M ES DE LA C O N S T R U C C I O N N 